\title{
Low-temperature fabrication of HfAlO alloy dielectric using atomic-layer deposition and its application in a low-power device
}

DOI:

10.1016/j.jallcom.2019.04.015

\section{Document Version}

Accepted author manuscript

Link to publication record in Manchester Research Explorer

Citation for published version (APA):

Ma, P., Sun, J., Zhang, G., Liang, G., Xin, Q., Li, Y., \& Song, A. (2019). Low-temperature fabrication of HfAlO alloy dielectric using atomic-layer deposition and its application in a low-power device. Journal of Alloys and Compounds. https://doi.org/10.1016/j.jallcom.2019.04.015

Published in:

Journal of Alloys and Compounds

\section{Citing this paper}

Please note that where the full-text provided on Manchester Research Explorer is the Author Accepted Manuscript or Proof version this may differ from the final Published version. If citing, it is advised that you check and use the publisher's definitive version.

\section{General rights}

Copyright and moral rights for the publications made accessible in the Research Explorer are retained by the authors and/or other copyright owners and it is a condition of accessing publications that users recognise and abide by the legal requirements associated with these rights.

\section{Takedown policy}

If you believe that this document breaches copyright please refer to the University of Manchester's Takedown Procedures [http://man.ac.uk/04Y6Bo] or contact uml.scholarlycommunications@manchester.ac.uk providing relevant details, so we can investigate your claim.

\section{OPEN ACCESS}




\section{Low-temperature fabrication of HfAlO alloy dielectric using atomic-layer deposition and its application in a low-power device}

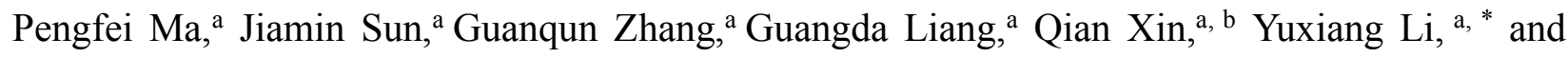
Aimin Song, b, c, *

${ }^{a}$ Center of Nanoelectronics and School of Microelectronics, Shandong University, Jinan 250100, China

${ }^{b}$ State Key Laboratory of Crystal Materials, Shandong University, Jinan 250100, China

${ }^{c}$ School of Electrical and Electronic Engineering, University of Manchester, Manchester M13 9PL, United Kingdom

\section{ABSTRACT}

This paper presents a systematic study of HfAlO alloy films, which were prepared by doping $\mathrm{HfO}_{2}$ with different amounts of $\mathrm{Al}$ using atomic layer deposition at low growth temperature $\left(150{ }^{\circ} \mathrm{C}\right)$. The chemical constituents of the various HfAlO films were determined by $\mathrm{X}$-ray photoelectron spectroscopy. Carrier transport through the HfAlO layer presented a good fit with the Poole-Frenkel emission and Fowler-Nordheim tunnelling mechanisms in different voltage ranges. Barrier heights (conduction band offset) between the HfAlO films and Si substrate, which were derived from the Fowler-Nordheim fittings, increased with increasing Al content in the alloy films, and the leakage current was suppressed well owing to the higher barrier. The $10 \mathrm{~nm}$ $\mathrm{HfAlO}$ dielectric layer, which was grown by the repeated deposition of 1 cycle each of $\mathrm{HfO}_{2}$ and $\mathrm{Al}_{2} \mathrm{O}_{3}$ (defined as $\mathrm{H} 1 \mathrm{~A} 1$ ), showed a high gate capacitance of $723 \mathrm{nF} / \mathrm{cm}^{2}$, a high breakdown voltage of $8.0 \mathrm{~V}$, a small leakage current, and a smooth surface. HfAlO films doped with different amounts of $\mathrm{Al}_{2} \mathrm{O}_{3}$ in $\mathrm{HfO}_{2}$ were employed to study their effects on the operation of amorphous indium-gallium-zinc oxide (a-IGZO) thin-film transistors (TFTs). The a-IGZO TFTs based on 
the H1A1 gate dielectric showed desirable properties including a high $I_{\text {on/off }}$ ratio of $1.7 \times 10^{7}$, a small subthreshold swing of $176 \mathrm{mV} /$ decade, and low operating voltage of $2.0 \mathrm{~V}$.

\section{Keywords:}

HfAlO, High- $k$ gate insulator, a-InGaZnO, Thin-film transistor, Atomic layer deposition, Low-power device

\section{Introduction}

The material $\mathrm{HfO}_{2}$ has been widely used and investigated in transistors [1-3], ferroelectric memory [4], and resistive random memory [5, 6], owing to its high dielectric constant $(k=$ 20-25), relatively large band gap $(\sim 5.8 \mathrm{eV})$, and compatibility with current semiconductor technologies. However, $\mathrm{HfO}_{2}$ has some unavoidable disadvantages, i.e., $\mathrm{HfO}_{2}$ film contains a high concentration of oxygen vacancies and oxygen interstitials, which cause many shallow traps in the film, and it has a low crystallisation temperature [7]. To overcome these shortcomings, additional dopants, such as, $\mathrm{Si}, \mathrm{La}$, and $\mathrm{Al}$ are introduced into $\mathrm{HfO}_{2}$ to form $\mathrm{Hf}-$ based hybrid materials, which have been employed in microelectronic devices [8-10]. Researchers have devoted considerable attention to $\mathrm{HfAlO}$ films (fabricated by incorporating $\mathrm{Al}_{2} \mathrm{O}_{3}$ in $\mathrm{HfO}_{2}$ films), which effectively suppressed the interface trap density $\left(D_{\mathrm{it}}\right)$ and increased the band gap and the breakdown field [11]. Band alignment between HfAlO and the semiconductor is of great importance for MOSFET applications, which could improve the barrier height for carriers and reduce the leakage currents $[12,13]$. The properties of the interface between HfAlO and different films, for instance, graphene [14], InP [12], $\mathrm{Ga}_{2} \mathrm{O}_{3}$ [11], and $\mathrm{Ge}$ [13], have also been widely studied. Furthermore, researchers have explored the influence of the chemical composition of 
HfAlO films [15], and investigated the effects of the thermal stability on annealing temperature $[16,17]$. HfAlO films have been grown by diverse methods such as solution-process [18], sputtering [19, 20], and atomic layer deposition (ALD) [12, 21, 22]. Among these alternative technologies, ALD is a technique to fabricate films by way of chemical vapour deposition and is based on ordered and self-saturated surface reactions. ALD is an effective and important method that allows dense, smooth, and highly conformal films to be fabricated with angstrom-precision thickness control [23]. HfAlO films grown by ALD play important roles in memory devices, especially in NAND flash memories [24], and resistive random memory devices [25]. Furthermore, $\mathrm{HfO}_{2}$-based materials have been used as the gate dielectric as a replacement for conventional $\mathrm{SiO}_{2}$ to improve the device performance and realise the low-voltage operation of transistors $[26,27]$.

Thin-film transistors (TFTs) are regarded as important components in electronic devices, and amorphous indium-gallium-zinc oxide (a-IGZO) has been widely studied for the fabrication of TFTs owing to its excellent performance in terms of stability, high electron mobility, low off current, surface smoothness, and low processing temperature [28, 29], Emerging applications of a-IGZO TFTs, such as sensors [30], wearable electronics [31], and thin-film circuits [32, 33] have attracted considerable attention for use in flexible devices, because of the ease of deposition of a-IGZO on a flexible substrate. When developing flexible devices and circuits, the identification of a befitting dielectric that can be deposited at low temperature is crucial, owing to the temperature-sensitive nature of flexible substrates $[34,35]$. The use of solution-induced HfAlO film has also been used in low-voltage-operating InZnO TFTs, while, high-temperature annealing was needed to realise a low leakage current [18]. HfAlO alloy could be a promising dielectric for use in low operating voltage a-IGZO TFTs, which may be powered by lithium ion 
batteries. [36-39] It is worthwhile to fabricate high-quality HfAlO alloy films grown by ALD at low temperature and to study its applications in low-power a-IGZO TFTs.

In this study, three HfAlO films, consisting of $\mathrm{HfO}_{2}$ doped with different amounts of $\mathrm{Al}$, were grown using ALD at $150{ }^{\circ} \mathrm{C}$. The chemical bonding states of the HfAlO films have been investigated by using X-ray photoelectron spectroscopy (XPS). Metal-insulator-semiconductor (MIS) capacitors were fabricated to study the electron transport mechanism and measure the robustness of the HfAlO films. Current-voltage $(I-V)$ and capacitance-voltage $(C-V)$ measurements were conducted to explore the electrical characteristics of HfAlO films. The a-IGZO TFTs, based on a HfAlO gate dielectric layer, exhibit excellent properties, and show promise for use in future electronic devices with low power consumption requirements.

\section{Experimental}

In this work, we fabricated various HfAlO alloy dielectric films by using ALD at a growth temperature of $150^{\circ} \mathrm{C}$. The HfAlO films were grown using a sequence of $x \mathrm{HfO}_{2}$ cycles followed by $y \mathrm{Al}_{2} \mathrm{O}_{3}$ cycles, and this process was repeated $n$ times to achieve a thickness of $10 \mathrm{~nm}$. The three types of HfAlO films are denoted as HxAy, i.e., H2A1, H1A1, H1A2. Two control samples only including either $\mathrm{HfO}_{2}$ or $\mathrm{Al}_{2} \mathrm{O}_{3}$ were also used for comparison purposes. For the $\mathrm{HfO}_{2}$ cycle, tetrakis(dimethylamino)hafnium (TDMAH) and deionised $\mathrm{H}_{2} \mathrm{O}$ were selected as the metal precursor and oxygen source, respectively. Similarly, trimethylaluminium (TMA) and deionised $\mathrm{H}_{2} \mathrm{O}$ were used for the $\mathrm{Al}_{2} \mathrm{O}_{3}$ deposition. During film growth, high purity $\mathrm{N}_{2}$ was used as the carrier gas with which to introduce the precursors to the reactor chamber and the pressure in the chamber was kept at 0.2 Torr. The dose time of TDMAH, TMA, and $\mathrm{H}_{2} \mathrm{O}$ was $0.3 \mathrm{~s}, 0.03 \mathrm{~s}$ and $0.015 \mathrm{~s}$, respectively. Every dose operation was followed by a $30 \mathrm{~s}$ purging process. The chemical 
bonding states of the HfAlO films were examined by XPS with ThermoFisher ESCALAB 250 equipment. The different HfAlO alloy films were employed in a-IGZO TFTs as the gate dielectric layers, which were first grown by ALD on heavily doped n-type Si substrates. Following the deposition of HfAlO film, a 24-nm a-IGZO $\left(\operatorname{In}_{2} \mathrm{O}_{3}: \mathrm{Ga}_{2} \mathrm{O}_{3}: \mathrm{ZnO}=1: 1: 1 \mathrm{~mol}\right.$. \%) channel layer was deposited by radio-frequency (RF) sputtering at room temperature. During the sputtering, the RF power and Ar pressure were maintained at $90 \mathrm{~W}$ and 3.65 mTorr, respectively. Finally, 100-nm Al source and drain contact electrodes were deposited by thermal evaporation. The channel length $(60 \mu \mathrm{m})$ and width $(2000 \mu \mathrm{m})$ of the a-IGZO TFTs were defined by a shadow mask. Before the electrical measurements, the TFTs were annealed in air at $150{ }^{\circ} \mathrm{C}$ for $1 \mathrm{~h}$. The capacitance of the dielectrics and carrier transport mechanisms were explored by fabricating an MIS capacitor with different dielectrics using a shadow mask and thermal evaporation. $I-V$ and $C-V$ measurements were conducted to explore the performance of the devices using Agilent B2900 equipment and an E4980A Precision LCR Meter. The HfAlO film morphology and surface roughness was determined by atomic-force microscopy (AFM) and reported for an area of $10 \times 10 \mu \mathrm{m}^{2}$.

\section{Results and discussion}

The chemical constituents and element binding energy of various HfAlO films were first determined by XPS. Fig. 1 shows the X-ray photoelectron spectra of the Al 2p, Hf 4f, and O 1s core levels of the $\mathrm{Al}_{2} \mathrm{O}_{3}$ and $\mathrm{HfO}_{2}$ films. The binding energy was calibrated with the position of the $\mathrm{C} 1 \mathrm{~s}$ peak at $284.8 \mathrm{eV}$. For the $\mathrm{Al}_{2} \mathrm{O}_{3}$ film, Fig. 1(a) shows the $\mathrm{Al} 2 \mathrm{p}$ peak, which is fitted as a single peak at $74.9 \mathrm{eV}$. The $\mathrm{O} 1 \mathrm{~s}$ peak is located at $531.6 \mathrm{eV}$, as shown in Fig. 1(b), which is fitted well as a symmetrical single Al-O peak. The peak positions of $\mathrm{Hf} 4 \mathrm{f}_{5 / 2}, \mathrm{Hf} 4 \mathrm{f}_{7 / 2}$, and $\mathrm{O} 1 \mathrm{~s}$ 
for $\mathrm{HfO}_{2}$ films were fitted at $18.5 \mathrm{eV}, 16.8 \mathrm{eV}$ and $530.0 \mathrm{eV}$, respectively, as shown in Figs. 1(c) and $1(\mathrm{~d})$. The binding energy of the $\mathrm{Al}-\mathrm{O}$ bond $(531.6 \mathrm{eV})$ is obviously larger than that of the $\mathrm{Hf}-\mathrm{O}$ bond $(530.0 \mathrm{eV})$, which means that $\mathrm{Hf}$ is a more ionic cation than $\mathrm{Al}[40]$. The $\mathrm{Al} 2 \mathrm{p}, \mathrm{Hf} 4 \mathrm{f}$, and $\mathrm{O} 1 \mathrm{~s}$ peak positions in the various HfAlO films are summarised in Figs. 2(a), 2(b), and 2(c). All peaks of $\mathrm{Al} 2 \mathrm{p}$, Hf $4 \mathrm{f}$, and $\mathrm{O} 1 \mathrm{~s}$ were observed to shift to a higher binding energy as the $\mathrm{Al}_{2} \mathrm{O}_{3}$ concentration in $\mathrm{HfAlO}$ films increased, indicating enhanced incorporation of the $\mathrm{Al}_{2} \mathrm{O}_{3}$ and $\mathrm{HfO}_{2}$ layers and the formation of $\mathrm{Hf}-\mathrm{O}-\mathrm{Al}$ bonding. The position of the $\mathrm{Al} 2 \mathrm{p}$ peak shifted from $74.1 \mathrm{eV}$ in $\mathrm{H} 2 \mathrm{~A} 1$ to $74.6 \mathrm{eV}$ in $\mathrm{H} 1 \mathrm{~A} 2$, while the $\mathrm{Hf} 4 \mathrm{f}$ peaks shifted from $17.2 \mathrm{eV}$ and $18.7 \mathrm{eV}$ in H2A1 to $17.8 \mathrm{eV}$ and $19.3 \mathrm{eV}$ in H1A2. The chemical compositions of various HfAlO films were determined by the elemental peak intensity in the XPS spectra. The detailed statistical compositions of the five films are provided in Table 1 . The $\mathrm{HfO}_{2}$ mole fraction values in the $\mathrm{H} 2 \mathrm{~A} 1, \mathrm{H} 1 \mathrm{~A} 1$, and $\mathrm{H} 1 \mathrm{~A} 2$ dielectric layers, $0.60,0.45$, and 0.31 , respectively, were obtained by calculation [40].
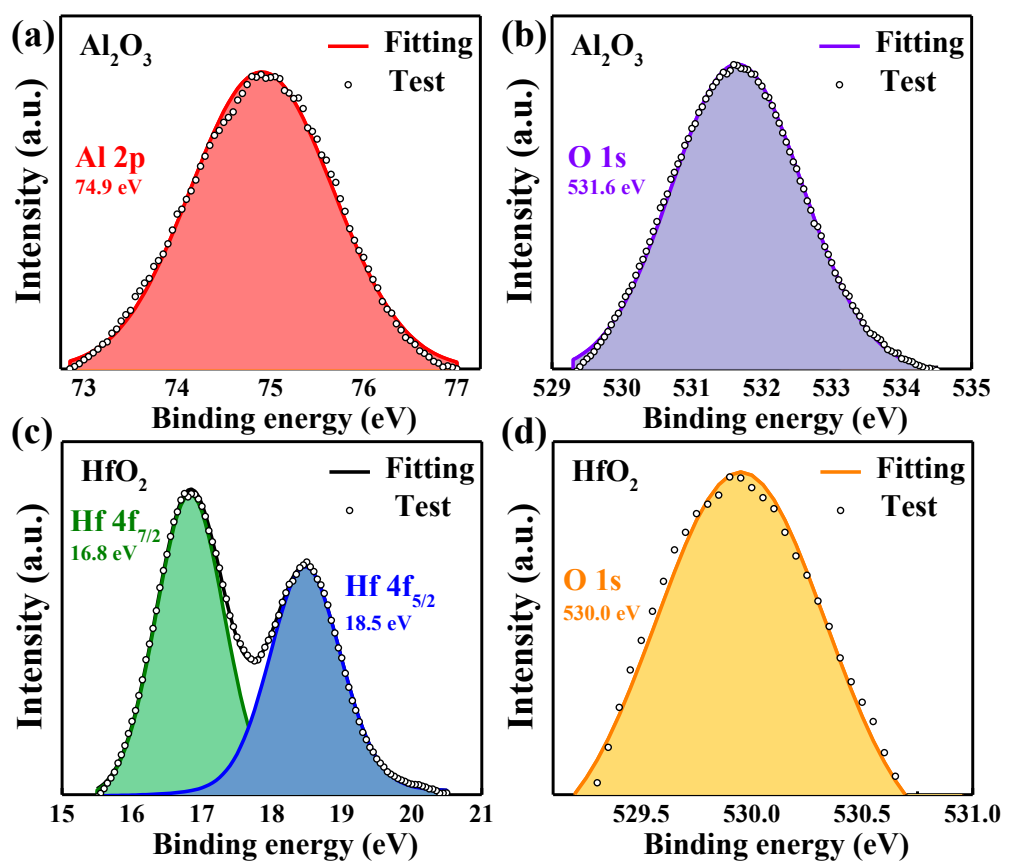

Fig. 1. XPS results of the (a) $\mathrm{Al} 2 \mathrm{p}$ and (b) $\mathrm{O} 1 \mathrm{~s}$ core levels for $\mathrm{Al}_{2} \mathrm{O}_{3}$ film, and (c) $\mathrm{Hf} 4 \mathrm{f}$ and (d) $\mathrm{O} 1 \mathrm{~s}$ core levels for $\mathrm{HfO}_{2}$ film. 
Table 1 Elemental composition of HfAlO films estimated by XPS and the mole fraction of $\mathrm{HfO}_{2}$ in $\mathrm{HfAlO}$

\begin{tabular}{llllll}
\hline & $\mathrm{HfO}_{2}$ & $\mathrm{H} 2 \mathrm{~A} 1$ & $\mathrm{H} 1 \mathrm{~A} 1$ & $\mathrm{H} 1 \mathrm{~A} 2$ & $\mathrm{Al}_{2} \mathrm{O}_{3}$ \\
\hline $\mathrm{HfO}_{2}$ mole fraction & & & & & \\
value in HfAlO & 1 & $\sim 0.60$ & $\sim 0.45$ & $\sim 0.31$ & 0 \\
\hline Hafnium at.\% & $32.8 \%$ & $15.8 \%$ & $11.0 \%$ & $7.0 \%$ & 0 \\
\hline Aluminium at.\% & 0 & $18.4 \%$ & $26.1 \%$ & $31.7 \%$ & $40.1 \%$ \\
\hline Oxygen at.\% & $67.2 \%$ & $65.8 \%$ & $62.9 \%$ & $61.3 \%$ & $59.9 \%$ \\
\hline
\end{tabular}

The ALD process we developed was designed with the aim of achieving $\mathrm{Hf}-\mathrm{O}-\mathrm{Al}$ bonding. $\mathrm{HfO}_{2}$ film growth is represented by two reaction equations:

$$
\begin{gathered}
\mathrm{Hf}-\mathrm{OH}+\mathrm{Hf}\left[\mathrm{N}\left(\mathrm{CH}_{3}\right)_{2}\right]_{4} \rightarrow \mathrm{Hf}-\mathrm{O}-\mathrm{Hf}\left[\mathrm{N}\left(\mathrm{CH}_{3}\right)_{2}\right]_{3}+\left(\mathrm{CH}_{3}\right)_{2} \mathrm{NH}, \\
\mathrm{Hf}-\mathrm{N}\left(\mathrm{CH}_{3}\right)_{2}+\mathrm{H}_{2} \mathrm{O} \rightarrow \mathrm{Hf}-\mathrm{OH}+\left(\mathrm{CH}_{3}\right)_{2} \mathrm{NH} .
\end{gathered}
$$

Similarly, $\mathrm{Al}_{2} \mathrm{O}_{3}$ film growth can be expressed by two reaction equations:

$$
\begin{gathered}
\mathrm{Al}-\mathrm{OH}+\mathrm{Al}\left(\mathrm{CH}_{3}\right)_{3} \rightarrow \mathrm{Al}-\mathrm{O}-\mathrm{Al}\left(\mathrm{CH}_{3}\right)_{2}+\mathrm{CH}_{4}, \\
\mathrm{Al}-\mathrm{CH}_{3}+\mathrm{H}_{2} \mathrm{O} \rightarrow \mathrm{Al}-\mathrm{OH}+\mathrm{CH}_{4} .
\end{gathered}
$$

Hf-O-Al bonding may be formed by combining $\mathrm{Hf}-\mathrm{OH}$ and $\mathrm{Al}\left(\mathrm{CH}_{3}\right)_{3}$ between Eqs. (2) and (3) or $\mathrm{Al}-\mathrm{OH}$ and $\mathrm{Hf}\left[\mathrm{N}\left(\mathrm{CH}_{3}\right)_{2}\right]_{4}$ between Eqs. (4) and (1). The position of the $\mathrm{O}$ 1s peak for $\mathrm{Hf}-\mathrm{O}-\mathrm{Al}$ bonding was fitted at $530.9 \mathrm{eV}$ and the peak intensity increases as the amount of incorporated Al increases, as shown in Fig. 2(c). The oxygen vacancies may be reduced with the formation of $\mathrm{Hf}-\mathrm{O}-\mathrm{Al}$ bonding, which could decrease the number of defects and suppress the leakage current through the HfAlO alloy film. 

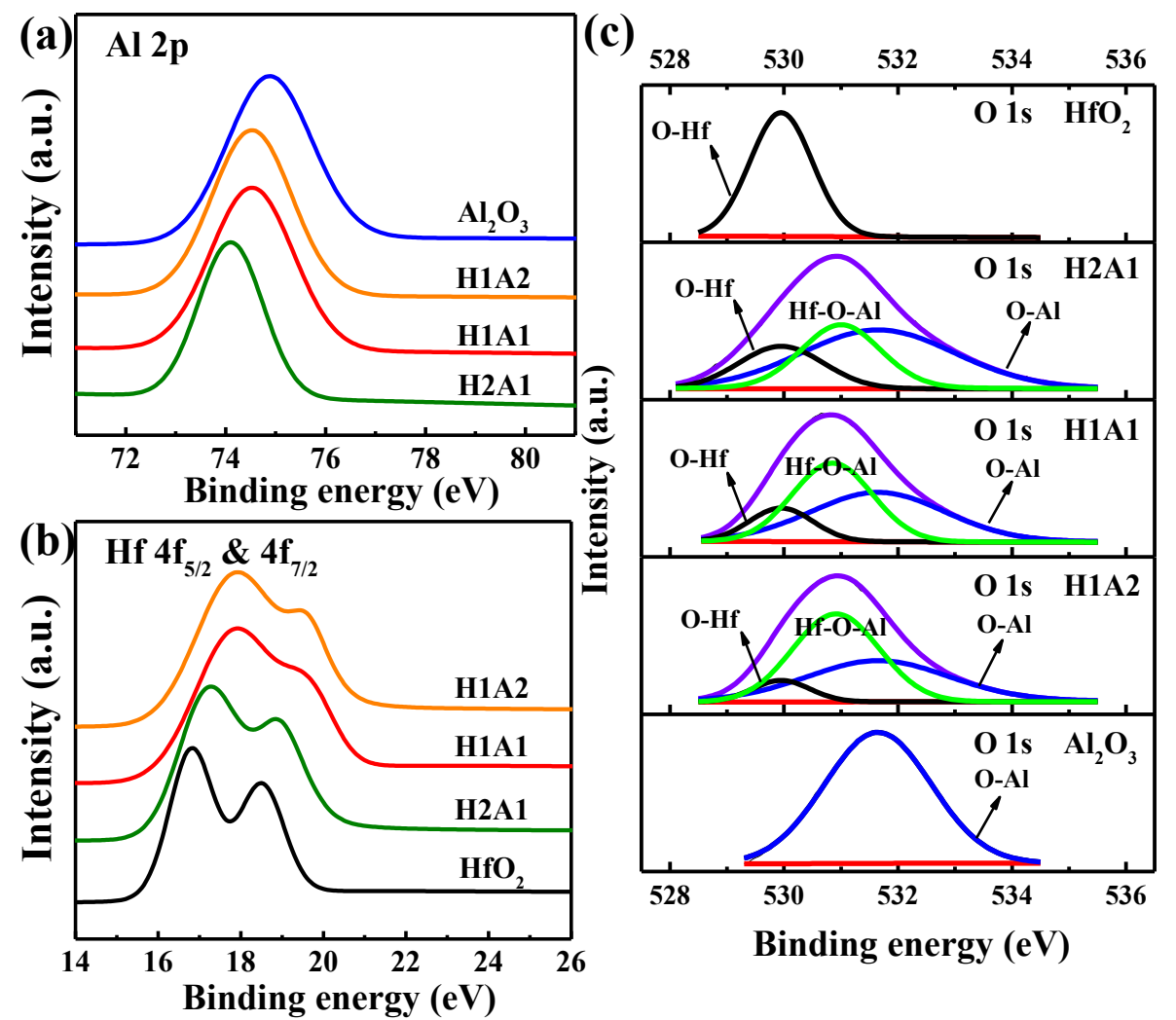

Fig. 2. XPS spectra for (a) Al 2p, (b) Hf 4f, and (c) O 1s core levels from HfAlO films.

To study the electron transport mechanism and measure the robustness of the HfAlO films, MIS capacitors were fabricated and relatively large voltages were applied to the devices. The $I-V$ characteristics of the capacitors are shown in Fig. 3(a) and a schematic diagram is shown as the inset. The leakage currents can be seen to decrease with increasing Al content of the HfAlO films and the breakdown voltages for various $\mathrm{HfAlO}$ films are all greater than that of $\mathrm{HfO}_{2}$ film, which may be caused by the decreasing number of defects. We carried out an in-depth analysis of the leakage mechanism by fitting the $I-V$ curves by different models. Possible mechanisms include direct tunnelling, Schottky emission, Poole-Frenkel (P-F) emission, and Fowler-Nordheim (F-N) tunnelling.

$\mathrm{P}-\mathrm{F}$ emission occurs because of the emission of trapped electrons into the conduction band. The $I-V$ curve is given by 


$$
I \propto V \exp \left[\frac{q}{k T}\left(2 a \sqrt{V}-\phi_{0}\right)\right],
$$

where $a$ is a constant, $q$ is the electron charge, and $\phi_{0}$ is the barrier height [41].

The $\mathrm{F}-\mathrm{N}$ tunnelling current is given by the following formula

$$
\frac{J}{E^{2}}=C_{1} e^{-C_{2} / E}
$$

Where $C_{1}$ and $C_{2}$ are given by

$$
\begin{aligned}
& C_{1}=q^{3} m / 16 \pi^{2} \hbar m_{\mathrm{ox}} \phi_{0}, \\
& C_{2}=\frac{4}{3} \frac{\left(2 m_{\mathrm{ox}}\right)^{1 / 2}}{q \hbar} \phi_{0}^{\frac{3}{2}},
\end{aligned}
$$

where $J$ is the current density, $E$ is the electric field, $2 \pi \hbar$ is Planck's constant, and $m$ and $m_{\mathrm{ox}}$ are the electron mass in free space and in the oxide, respectively [42]. Further, $m_{\mathrm{ox}}$ is $0.23 m$ for $\mathrm{Al}_{2} \mathrm{O}_{3}$ and $0.17 m$ for $\mathrm{HfO}_{2}$, respectively $[43,44]$. As for HfAlO, $m_{\mathrm{ox}}$ is $0.20 m$.
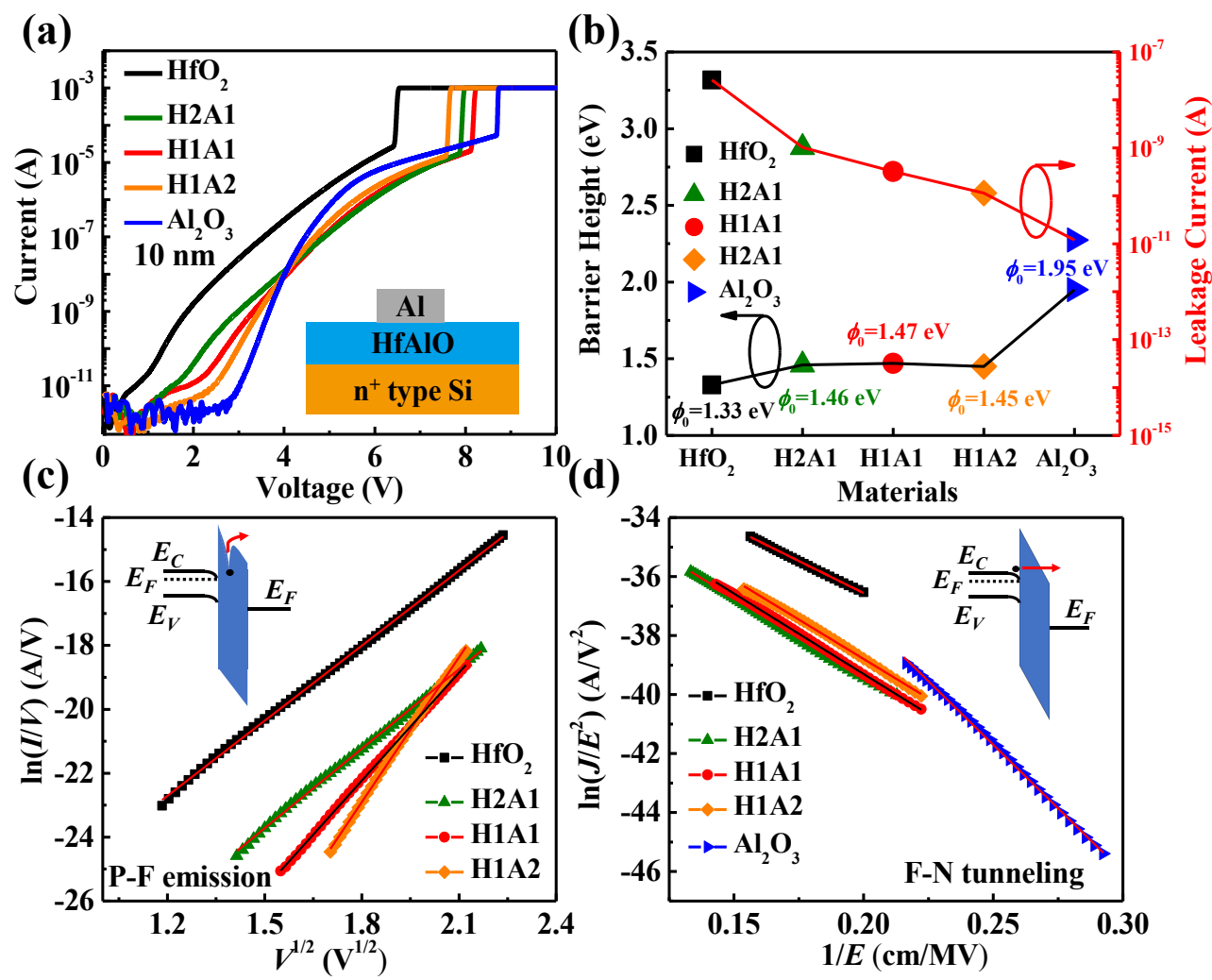

Fig. 3. (a) $I-V$ measurements of $\mathrm{Al} / \mathrm{HfAlO} / \mathrm{n}^{+}-\mathrm{Si}$ devices with different $\mathrm{Hf} / \mathrm{Al}$ ratios, and a compliance current of $10^{-3} \mathrm{~A}$ was set during the electrical measurements. (b) Statistics of the barrier heights and leakage currents at $3.0 \mathrm{~V}$ 
bias. Linear fittings of the leakage current by the (c) P-F emission and (d) F-N tunnelling models. The dotted lines are the experimental results and the solid lines are the fittings. The insets in Fig. $3 \mathrm{c}$ and Fig. 3d are the energy-band diagrams of the $\mathrm{P}-\mathrm{F}$ emission and $\mathrm{F}-\mathrm{N}$ tunnelling conduction mechanisms, respectively.

The leakage currents of the 10-nm thin films of HfAlO with different Hf/Al ratios are fitted by Eqs. (5) and (6), and the linear fittings are shown in Figs. 3(c) and 3(d), respectively. The fitted results indicate that, under a lower $E$, the carriers can traverse the films via shallow traps, and when $E$ is sufficiently strong, the energy of the carriers is such that they are able to partly tunnel through the barrier. The barrier height can be deduced from the $\mathrm{F}-\mathrm{N}$ fitting results. Details of the barrier heights and leakage currents at 3.0 V bias are plotted in Fig. 3(b). The barrier heights are $1.33,1.46,1.47,1.45$, and $1.95 \mathrm{eV}$ for $\mathrm{HfO}_{2}, \mathrm{H} 2 \mathrm{~A} 1, \mathrm{H} 1 \mathrm{~A} 1, \mathrm{H} 1 \mathrm{~A} 2$, and $\mathrm{Al}_{2} \mathrm{O}_{3}$, respectively. The barrier heights of the $\mathrm{H} 2 \mathrm{~A} 1, \mathrm{H} 1 \mathrm{~A} 1$, and $\mathrm{H} 1 \mathrm{~A} 2$ films are larger than that of the $\mathrm{HfO}_{2}$ film, which could also be responsible for suppressing the leakage current.

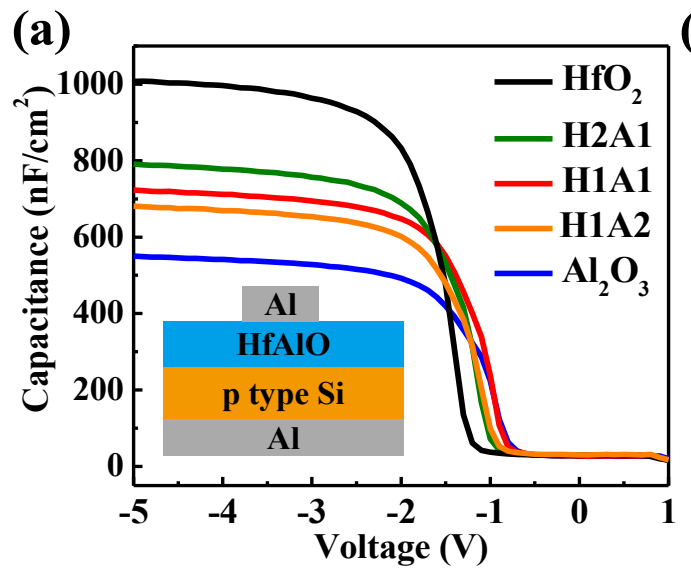

(b)

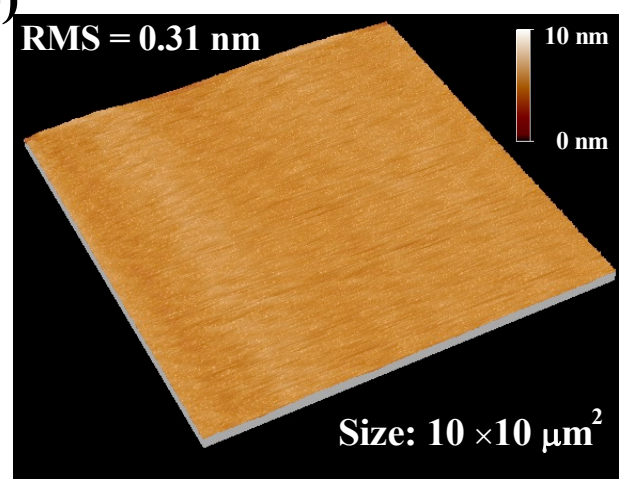

Fig. 4. (a) $C-V$ characteristics (main image) and structural diagram (inset) of $\mathrm{Al} / \mathrm{HfAlO} / \mathrm{p}-\mathrm{Si}$ capacitors with the five different dielectrics. (b) AFM image of $10 \mathrm{~nm}$ H1A1 film in a scan area $10 \times 10 \mu \mathrm{m}^{2}$.

Subsequently, Al/HfAlO/p-Si capacitors were fabricated to explore the capacitance of the HfAlO dielectrics $\left(C_{\text {ox }}\right)$. Fig. 4(a) and the inset show the $C-V$ characteristics and structural diagram of capacitors, respectively. The $C_{\mathrm{ox}}$ values of the HfAlO films ordered from large to 
small are $1010,791,723,680$, and $550 \mathrm{nF} / \mathrm{cm}^{2}$ for $\mathrm{HfO}_{2}, \mathrm{H} 2 \mathrm{~A} 1, \mathrm{H} 1 \mathrm{~A} 1, \mathrm{H} 1 \mathrm{~A} 2$, and $\mathrm{Al}_{2} \mathrm{O}_{3}$, respectively. The capacitance decreases as the percentage of $\mathrm{Al}$ in the dielectric film increases. The surface morphologies of the HfAlO dielectric films were also studied by AFM. Fig. 4(b) shows the AFM image of the 10-nm H1A1 film. HfAlO films were all prepared by ALD, which is based on ordered and self-saturated surface reactions and allows highly conformal films to be fabricated layer-by-layer with angstrom-precision thickness control. The root-mean-square (RMS) values of the roughness are $0.28,0.34,0.31,0.33$, and $0.25 \mathrm{~nm}$ for $\mathrm{HfO}_{2}, \mathrm{H} 2 \mathrm{~A} 1, \mathrm{H} 1 \mathrm{~A} 1$, $\mathrm{H} 1 \mathrm{~A} 2$, and $\mathrm{Al}_{2} \mathrm{O}_{3}$, respectively, which confirm the smooth surface morphology of our ALD films.

(a)

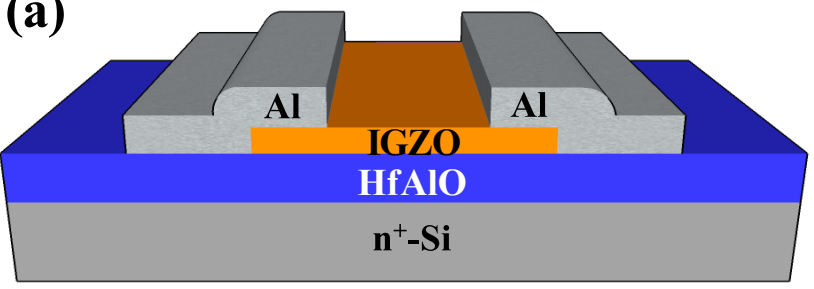

(b)

(c)
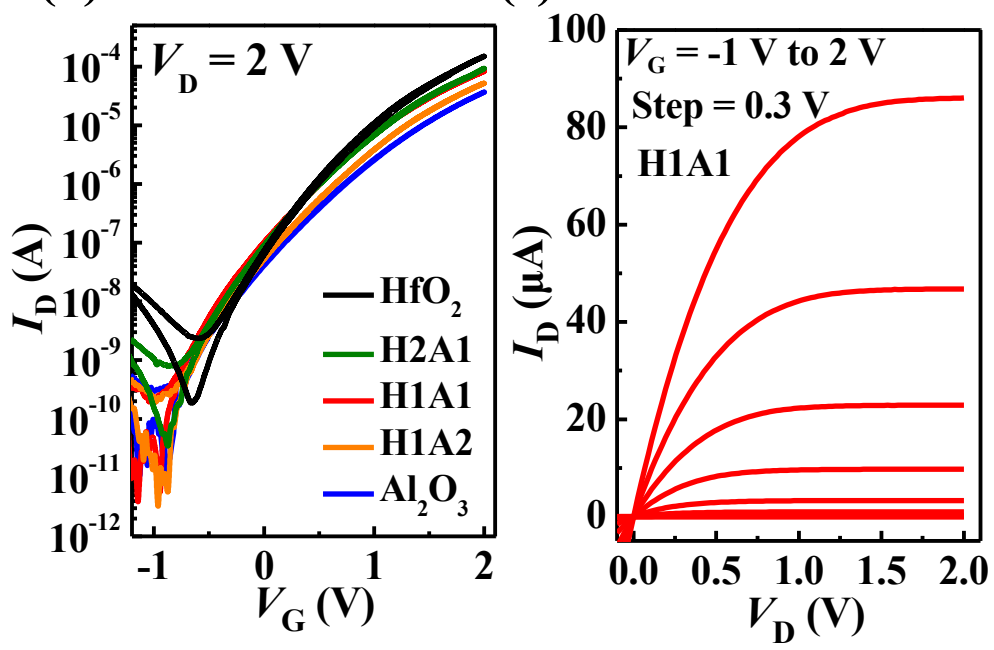

Fig. 5. (a) Structural diagram of a-IGZO TFTs. (b) Transfer characteristics of a-IGZO TFTs with different HfAlO gate dielectrics. (c) Output characteristics of the a-IGZO TFT with 10-nm H1A1.

The structural diagram and transfer characteristics of the a-IGZO TFTs with different HfAlO films as gate dielectrics are shown in Figs. 5(a) and 5(b), respectively. The interface between the channel layer and gate dielectric layer would be expected to influence the performance of the 
TFTs, especially the surface roughness of the gate dielectric material. As shown in Fig. 5(b), very little hysteresis is observed, which could be a benefit of the smooth surface of the dielectric layers and low density of slow interface traps [28]. However, a-IGZO TFTs with $10-\mathrm{nm} \mathrm{HfO}_{2}$ film as the gate dielectric layer experience a strong leakage current, resulting in that TFTs cannot be turned off successfully. This indicates that doping $\mathrm{HfO}_{2}$ with $\mathrm{Al}_{2} \mathrm{O}_{3}$ could suppress the leakage current effectively. In addition, large capacitance is necessary to operate these TFTs at low power. Therefore, H1A1 was selected as the optimal gate dielectric layer to maintain a high carrier mobility and large on/off ratio. As shown in Fig. 5(c), clear pinch-off behaviour can be found in the output curves of the a-IGZO TFT with the $10-\mathrm{nm}$ H1A1 dielectric. The $S S$ value is determined by the gate dielectric interface trap density $D_{\mathrm{it}}$, the bulk trap density in the semiconductor channel $N_{\text {bulk, }}$ and in the case with the non-encapsulated channel, also the top surface trap density of the semiconductor channel $D_{\text {top: }}$ :

$$
S S=\frac{k_{\mathrm{B}} T \ln 10}{q}\left[1+\frac{q^{2}}{C_{o x}} D_{\text {total }}\right]
$$

where $D_{\text {total }}=D_{\text {it }}+t N_{\text {bulk }}+D_{\text {top }}$, and $t$ is the thickness of the channel $[29,45]$. The $D_{\text {total }}$ values and other main characteristics of TFTs gated by different HfAlO layers are also compared in Table 2. The linear $\left(\mu_{\text {lin }}\right)$ and saturation $\left(\mu_{\mathrm{sat}}\right)$ mobility were extracted from the transfer curves at $V_{\mathrm{DS}}$ of 0.1 V and 2.0 V, respectively. The TFTs that contain 10-nm H1A1 exhibit desirable properties for low-power operations, including low threshold (or turn on) voltage $\left(V_{\mathrm{T}}=0.83 \mathrm{~V}\right)$, high saturation mobility $\left(\mu_{\text {sat }}=5.52 \pm 0.07 \mathrm{~cm}^{2} / \mathrm{Vs}\right)$ and linear mobility $\left(\mu_{\text {lin }}=4.52 \pm 0.06 \mathrm{~cm}^{2} / \mathrm{Vs}\right)$, a small subthreshold swing $(S S=176 \mathrm{mV} / \mathrm{dec})$, and a high on/off current ratio $\left(I_{\mathrm{on}} / I_{\mathrm{off}}=1.7 \times 10^{7}\right)$.

Table 2 Comparison of a-IGZO TFTs gated by different HfAlO dielectric layers. 


\begin{tabular}{ccccccc}
\hline Gate & $\mu_{\text {sat }}$ & $\mu_{\text {lin }}$ & $V_{\mathrm{T}}$ & $S S$ & & $N_{S S}^{\max }$ \\
dielectrics & $\left(\mathrm{cm}^{2} / \mathrm{Vs}\right)$ & $\left(\mathrm{cm}^{2} / \mathrm{Vs}\right)$ & $(\mathrm{V})$ & $(\mathrm{mV} / \mathrm{dec})$ & $I_{\mathrm{on}} / I_{\mathrm{off}}$ & \\
\hline $\mathrm{HfO}_{2}$ & $8.83 \pm 0.12$ & $7.58 \pm 0.10$ & 0.95 & $\ldots$ a & $7.6 \times 10^{6}$ & $\ldots$ a \\
$\mathrm{H} 2 \mathrm{~A} 1$ & $5.97 \pm 0.08$ & $4.94 \pm 0.07$ & 0.88 & 168 & $2.2 \times 10^{6}$ & $8.91 \times 10^{12}$ \\
$\mathrm{H} 1 \mathrm{~A} 1$ & $5.52 \pm 0.07$ & $4.52 \pm 0.06$ & 0.83 & 176 & $1.7 \times 10^{7}$ & $8.75 \times 10^{12}$ \\
$\mathrm{H} 1 \mathrm{~A} 2$ & $3.93 \pm 0.05$ & $2.98 \pm 0.04$ & 0.87 & 185 & $1.1 \times 10^{7}$ & $8.89 \times 10^{12}$ \\
$\mathrm{Al}_{2} \mathrm{O}_{3}$ & $3.68 \pm 0.05$ & $2.58 \pm 0.04$ & 0.91 & 195 & $7.3 \times 10^{6}$ & $7.75 \times 10^{12}$ \\
\hline
\end{tabular}

aParameter is difficult to extract because of poor device performance.

\section{Conclusions}

In summary, films of HfAlO alloys grown by ALD at low temperature with different $\mathrm{Al}$ content were studied for implementation as a gate dielectric for a-IGZO TFTs. The chemical constituents of various HfAlO films were determined by XPS. As the doping Al content of the HfAlO increased, the number of defects in the films decreased, the barrier height was enlarged, and the leakage current was suppressed to a satisfactory extent. The 10-nm H1A1 dielectric layer showed low surface roughness and a high breakdown voltage. Importantly, the a-IGZO TFTs based on H1A1 film exhibited desirable properties, including a steep subthreshold slope, negligible hysteresis, a high $I_{\mathrm{on} / \mathrm{off}}$ ratio, and a low operating voltage. In terms of carrier transport, the $\mathrm{P}-\mathrm{F}$ emission and $\mathrm{F}-\mathrm{N}$ tunnelling mechanisms were found to play important roles in different voltage ranges. The results confirm that our a-IGZO TFTs gated by an HfAlO alloy dielectric material show great promise for use in future low-power electronics applications. 


\section{Acknowledgement}

This work was financed by the National Key Research and Development Program of China (Grant Nos. 2016YFA0201800 and 2016YFA0301200), the National Natural Science Foundation of China (Grant Nos. 11374185, 11304180, 61250013), Engineering and Physical Sciences Research Council (Grant No. EP/N021258/1), China Postdoctoral Science Foundation (2015M582073 and 2016M590634), the Natural Science Foundation of Shandong Province (ZR2013EMQ011), the Natural Science Foundation of Jiangsu Province (BK20151255), Suzhou

Planning Projects of Science and Technology (SYG201527 and SYG201616), and the Fundamental Research Funds of Shandong University (2013TB008, 2014QY005 and 2016WLJH44).

\section{References}

[1] V. Raghuwanshi, D. Bharti, A.K. Mahato, I. Varun, S.P. Tiwari, Solution-Processed Organic Field-Effect Transistors with High Performance and Stability on Paper Substrates, ACS Appl. Mater. Interfaces 11 (2019) 8357-8364.

[2] C.-H. Cheng, C.-C. Fan, C.-Y. Tu, H.-H. Hsu, C.-Y. Chang, Implementation of Dopant-Free Hafnium Oxide Negative Capacitance Field-Effect Transistor, IEEE Trans. Electron Devices $66(2019) 825-828$.

[3] J.-P. Xu, W.-X. Xie, L. Liu, X. Zhao, X. Song, P.-T. Lai, W.-M. Tang, Effects of Trapped Charges in Gate Dielectric and High-k Encapsulation on Performance of $\mathrm{MoS}_{2}$ Transistor, IEEE Trans. Electron Devices 66 (2019) 1107-1112.

[4] T.Y. Lee, K. Lee, H.H. Lim, M.S. Song, S.M. Yang, H.K. Yoo, D.I. Suh, Z. Zhu, A. Yoon, M.R. MacDonald, X. Lei, H.Y. Jeong, D. Lee, K. Park, J. Park, S.C. Chae, Ferroelectric 
Polarization-Switching Dynamics and Wake-Up Effect in Si-Doped $\mathrm{HfO}_{2}$, ACS Appl. Mater. Interfaces 11 (2019) 3142-3149.

[5] P.-H. Chen, Y.-T. Su, F.-C. Chang, Stabilizing Resistive Switching Characteristics by Inserting Indium-Tin-Oxide Layer as Oxygen Ion Reservoir in $\mathrm{HfO}_{2}$-Based Resistive Random Access Memory, IEEE Trans. Electron Devices 66 (2019) 1276-1280.

[6] C.A. Lin, C.J. Huang, T.Y. Tseng, Impact of barrier layer on $\mathrm{HfO}_{2}$-based conductive bridge random access memory, Appl. Phys. Lett. 114 (2019) 093105.

[7] J. Robertson, R.M. Wallace, High-K materials and metal gates for CMOS applications, Mater. Sci. Eng. R 88 (2015) 1-41.

[8] Y.N. Gao, Y.L. Xu, J.G. Lu, J.H. Zhang, X.F. Li, Solution processable amorphous hafnium silicate dielectrics and their application in oxide thin film transistors, J. Mater. Chem. C 3 (2015) 11497-11504.

[9] S. Kothari, C. Joishi, S. Ghosh, D. Biswas, D. Vaidya, S. Ganguly, S. Lodha, Improved n-channel Ge gate stack performance using HfAlO high-k dielectric for various $\mathrm{Al}$ concentrations, Appl. Phys. Express 9 (2016) 071302.

[10] X. Xiong, X. Li, M. Huang, T. Li, T. Gao, Y. Wu, High Performance Black Phosphorus Electronic and Photonic Devices with HfLaO Dielectric, IEEE Electron Device Lett. 39 (2018) 127-130.

[11] L. Yuan, H.P. Zhang, R.X. Jia, L.X. Guo, Y.M. Zhang, Y.M. Zhang, Energy-band alignment of $\left(\mathrm{HfO}_{2}\right)_{(\mathrm{x})}\left(\mathrm{Al}_{2} \mathrm{O}_{3}\right)_{(1-\mathrm{x})}$ gate dielectrics deposited by atomic layer deposition on beta- $\mathrm{Ga}_{2} \mathrm{O}_{3}$ (-201), Appl. Surf. Sci. 433 (2018) 530-534.

[12] L. Yang, T. Wang, Y. Zou, H.-L. Lu, Band Offsets and Interfacial Properties of HfAlO Gate Dielectric Grown on InP by Atomic Layer Deposition, Nanoscale Res. Lett. 12 (2017) 339. 
[13] G. He, S. Jiang, W. Li, C. Zheng, H. He, J. Li, Z. Sun, Y. Liu, M. Liu, Interface chemistry and electronic structure of ALD-derived $\mathrm{HfAlO} / \mathrm{Ge}$ gate stacks revealed by X-ray photoelectron spectroscopy, J. Alloys Compd. 716 (2017) 1-6.

[14] S.B. Kim, Y.H. Ahn, J.-Y. Park, S.W. Lee, Enhanced nucleation and growth of $\mathrm{HfO}_{2}$ thin films grown by atomic layer deposition on graphene, J. Alloys Compd. 742 (2018) 676-682.

[15] J. Gao, G. He, Z. Sun, H. Chen, C. Zheng, P. Jin, D. Xiao, M. Liu, Modification of electrical properties and carrier transportation mechanism of ALD-derived $\mathrm{HfO}_{2} / \mathrm{Si}$ gate stacks by $\mathrm{Al}_{2} \mathrm{O}_{3}$ incorporation, J. Alloys Compd. 667 (2016) 352-358.

[16] L. Breuil, J.G. Lisoni, P. Blomme, G. Van den Bosch, J. Van Houdt, $\mathrm{HfO}_{2}$ Based High-k Inter-Gate Dielectrics for Planar NAND Flash Memory, IEEE Electron Device Lett. 35 (2014) $45-47$.

[17] X. Lan, X. Ou, Y. Cao, S. Tang, C. Gong, B. Xu, Y. Xia, J. Yin, A. Li, F. Yan, Z. Liu, The effect of thermal treatment induced inter-diffusion at the interfaces on the charge trapping performance of $\mathrm{HfO}_{2} / \mathrm{Al}_{2} \mathrm{O}_{3}$ nanolaminate-based memory devices, J. Appl. Phys. 114 (2013) 044104.

[18] G. He, W. Li, Z. Sun, M. Zhang, X. Chen, Potential solution-induced HfAlO dielectrics and their applications in low-voltage-operating transistors and high-gain inverters, RSC Adv. 8 (2018) 36584-36595.

[19] Z. Wu, Z. Yao, S. Liu, B. Yuan, Y. Zhang, Y. Liang, Z. Wang, X. Tang, G. Shao, Tuning the electrical performance of metal oxide thin-film transistors via dielectric interface trap passivation and graded channel modulation doping, J. Mater. Chem. C 5 (2017) 1206-1215.

[20] T. Guo, T. Tan, Z. Liu, B. Liu, Effects of Al dopants and interfacial layer on resistive switching behaviors of $\mathrm{HfO}_{\mathrm{x}}$ film, J. Alloys Compd. 708 (2017) 23-28. 
[21] H. Dong, W. Mu, Y. Hu, Q. He, B. Fu, H. Xue, Y. Qin, G. Jian, Y. Zhang, S. Long, Z. Jia, H. Lv, Q. Liu, X. Tao, M. Liu, C-V and J-V investigation of $\mathrm{HfO}_{2} / \mathrm{Al}_{2} \mathrm{O}_{3}$ bilayer dielectrics MOSCAPs on (OW) beta-Ga2 $\mathrm{O}_{3}$, AIP Adv. 8 (2018) 065215.

[22] G. He, W.D. Li, H.H. Wei, S.S. Jiang, X.D. Xiao, P. Jin, J. Gao, Modulation of electrical properties and current conduction mechanism of $\mathrm{HfAlO} / \mathrm{Ge}$ gate stack by ALD-derived $\mathrm{Al}_{2} \mathrm{O}_{3}$ passivation layer, J. Alloys Compd. 695 (2017) 1591-1599.

[23] V. Miikkulainen, M. Leskela, M. Ritala, R.L. Puurunen, Crystallinity of inorganic films grown by atomic layer deposition: Overview and general trends, J. Appl. Phys. 113 (2013) 021301

[24] Z. Hou, Z. Wu, H. Yin, The Effect of Thermal Treatment Induced Performance Improvement for Charge Trapping Memory with $\mathrm{Al}_{2} \mathrm{O}_{3} /\left(\mathrm{HfO}_{2}\right)(0.9)\left(\mathrm{Al}_{2} \mathrm{O}_{3}\right)(0.1) / \mathrm{Al}_{2} \mathrm{O}_{3}$ Multilayer Structure, Ecs Journal of Solid State Science and Technology 7 (2018) Q229-Q234.

[25] E. Perez, A. Grossi, C. Zambelli, P. Olivo, R. Roelofs, C. Wenger, Reduction of the Cell-to-Cell Variability in Hf1-xAlxOy Based RRAM Arrays by Using Program Algorithms, IEEE Electron Device Lett. 38 (2017) 175-178.

[26] P. Ma, J. Sun, G. Liang, Y. Li, Q. Xin, Y. Li, A. Song, Half-volt Operation of IGZO Thin-Film Transistors Enabled by Ultrathin $\mathrm{HfO}_{2}$ Gate Dielectric, Appl. Phys. Lett. 113 (2018) 063501.

[27] Y. Song, R. Xu, J. He, S. Siontas, A. Zaslavsky, D.C. Paine, Top-Gated Indium-Zinc-Oxide Thin-Film Transistors With In Situ $\mathrm{Al}_{2} \mathrm{O}_{3} / \mathrm{HfO}_{2}$ Gate Oxide, IEEE Electron Device Lett. 35 (2014) 1251-1253.

[28] P. Ma, L. Du, Y. Wang, R. Jiang, Q. Xin, Y. Li, A. Song, Low Voltage Operation of IGZO Thin Film Transistors Enabled by Ultrathin $\mathrm{Al}_{2} \mathrm{O}_{3}$ Gate Dielectric, Appl. Phys. Lett. 112 
(2018) 023501.

[29] B. Zhang, H. Li, X. Zhang, Y. Luo, Q. Wang, A. Song, Performance regeneration of InGaZnO transistors with ultra-thin channels, Appl. Phys. Lett. 106 (2015) 093506.

[30] C. Xin, L. Chen, T. Li, Z. Zhang, T. Zhao, X. Li, J. Zhang, Highly Sensitive Flexible Pressure Sensor by the Integration of Microstructured PDMS Film With a-IGZO TFTs, IEEE Electron Device Lett. 39 (2018) 1073-1076.

[31] W.J. Kang, C.H. Ahn, K.S. Kim, S.H. Jung, S.W. Cho, H.K. Cho, Y. Kim, Development of extremely low temperature processed oxide thin film transistors via atmospheric steam reforming treatment: Interface, surface, film curing, J. Alloys Compd. 744 (2018) 23-33.

[32] Y. Li, J. Yang, Y. Wang, P. Ma, Y. Yuan, J. Zhang, Z. Lin, L. Zhou, Q. Xin, A. Song, Complementary Integrated Circuits Based on p-Type SnO and n-Type IGZO Thin-Film Transistors, IEEE Electron Device Lett. 39 (2018) 208-211.

[33] J. Yang, Y. Wang, Y. Li, Y. Yuan, Z. Hu, P. Ma, L. Zhou, Q. Wang, A. Song, Q. Xin, Highly Optimized Complementary Inverters Based on p-SnO and n-InGaZnO With High Uniformity, IEEE Electron Device Lett. 39 (2018) 516-519.

[34] F.S. Stinner, Y. Lai, D.B. Straus, B.T. Diroll, D.K. Kim, C.B. Murray, C.R. Kagan, Flexible, High-Speed CdSe Nanocrystal Integrated Circuits, Nano Lett. 15 (2015) 7155-7160.

[35] W. Honda, T. Arie, S. Akita, K. Takei, Mechanically Flexible and High-Performance CMOS Logic Circuits, Sci. Rep. 5 (2015) 15099.

[36] X. Chen, Y. Huang, K. Zhang, X. Feng, M. Wang, Porous $\mathrm{TiO}_{2}$ nanobelts coated with mixed transition-metal oxides $\mathrm{Sn}_{3} \mathrm{O}_{4}$ nanosheets core-shell composites as high-performance anode materials of lithium ion batteries, Electrochim. Acta 259 (2018) 131-142.

[37] X. Chen, Y. Huang, K. Zhang, Cobalt nanofibers coated with layered nickel silicate coaxial 
core-shell composites as excellent anode materials for lithium ion batteries, J. Colloid Interface Sci. 513 (2018) 788-796.

[38] S. Zhang, J. Chen, T. Tang, Y. Jiang, G. Chen, Q. Shao, C. Yan, T. Zhu, M. Gao, Y. Liu, H. Pan, A novel strategy to significantly enhance the initial voltage and suppress voltage fading of a Li- and Mn-rich layered oxide cathode material for lithiumion batteries, Journal of Materials Chemistry A 6 (2018) 3610-3624.

[39] X. Ruan, Y. Yang, K. Pu, M. Gao, Y. Liu, H. Pan, Superior long-term cyclability of a nanocrystalline $\mathrm{NiO}$ anode enabled by a mechanochemical reaction-induced amorphous protective layer for Li-ion batteries, J. Power Sources 397 (2018) 134-142.

[40] H.Y. Yu, M.F. Li, B.J. Cho, C.C. Yeo, M.S. Joo, D.L. Kwong, J.S. Pan, C.H. Ang, J.Z. Zheng, S. Ramanathan, Energy gap and band alignment for $\left(\mathrm{HfO}_{2}\right)_{(\mathrm{x})}\left(\mathrm{Al}_{2} \mathrm{O}_{3}\right)_{(1-\mathrm{x})}$ on (100) Si, Appl. Phys. Lett. 81 (2002) 376-378.

[41] Y. Takahashi, K. Ohnishi, Estimation of Insulation Layer Conductance in MNOS Structure, IEEE Trans. Electron Devices 40 (1993) 2006-2010.

[42] M. Lenzlinger, E.H. Snow, Fowler-Nordheim Tunneling into Thermally Grown $\mathrm{SiO}_{2}$, J. Appl. Phys. 40 (1969) 278-283.

[43] A. Hiraiwa, D. Matsumura, H. Kawarada, Space-charge-controlled field emission model of current conduction through $\mathrm{Al}_{2} \mathrm{O}_{3}$ films, J. Appl. Phys. 119 (2016) 064505

[44] Y.-C. Yeo, T.-J. King, C. Hu, Direct tunneling leakage current and scalability of alternative gate dielectrics, Appl. Phys. Lett. 81 (2002) 2091-2093.

[45] L. Shao, K. Nomura, T. Kamiya, H. Hosono, Operation Characteristics of Thin-Film Transistors Using Very Thin Amorphous In-Ga-Zn-O Channels, Electrochem. Solid-State Lett. 14 (2011) H197-H200. 